\title{
Analysis of Different Series-Parallel Connection Modules for Dye-Sensitized Solar Cell by Electrochemical Impedance Spectroscopy
}

\author{
Jung-Chuan Chou, ${ }^{1,2}$ Chin-Hui Huang, ${ }^{2}$ Yi-Hung Liao, ${ }^{3}$ Yu-Jen Lin, ${ }^{2}$ \\ Chia-Ming Chu, ${ }^{1}$ and Yu-Hsun Nien ${ }^{4}$ \\ ${ }^{1}$ Department of Electronic Engineering, National Yunlin University of Science and Technology, Douliou, Yunlin 64002, Taiwan \\ ${ }^{2}$ Graduate School of Electronic Engineering, National Yunlin University of Science and Technology, Douliou, Yunlin 64002, Taiwan \\ ${ }^{3}$ Department of Information Management, TransWorld University, Yunlin 64063, Taiwan \\ ${ }^{4}$ Graduate School of Chemical and Materials Engineering, National Yunlin University of Science and Technology, \\ Douliou, Yunlin 64002, Taiwan
}

Correspondence should be addressed to Jung-Chuan Chou; choujc@yuntech.edu.tw

Received 30 December 2015; Accepted 24 April 2016

Academic Editor: Meenakshisundaram Swaminathan

Copyright (c) 2016 Jung-Chuan Chou et al. This is an open access article distributed under the Creative Commons Attribution License, which permits unrestricted use, distribution, and reproduction in any medium, provided the original work is properly cited.

\begin{abstract}
The internal impedances of different dye-sensitized solar cell (DSSC) models were analyzed by electrochemical impedance spectrometer (EIS) with an equivalent circuit model. The Nyquist plot was built to simulate the redox reaction of internal device at the heterojunction. It was useful to analyze the component structure and promote photovoltaic conversion efficiency of DSSC. The impedance of DSSC was investigated and the externally connected module assembly was constructed utilizing single cells on the scaled-up module. According to the experiment results, the impedance was increased with increasing cells connected in series. On the contrary, the impedance was decreased with increasing cells connected in parallel.
\end{abstract}

\section{Introduction}

Solar energy has become attractive as a promising solution for reducing emissions of greenhouse gases and providing clean energy. For these reasons, the dye-sensitized solar cell (DSSC) has been widely investigated owing to its simple fabrication, low cost, and promising properties [1-3]. Figure 1 displayed working principle diagram of the DSSC. (1) The electrons are injected from the photoexcited dye into titanium dioxide $\left(\mathrm{TiO}_{2}\right)$ layer when light illuminates the cell; (2) the electrons pass through from $\mathrm{TiO}_{2}$ /dye to the transparent conducting oxide and transport into the external circuit; (3) the sensitizer is regenerated by the electrolyte; (4) the electrolyte is regenerated by counter electrode; (5) excited-state decays to ground state; (6) recombination of the injected electrons with the oxidized dye; (7) recombination of the injected electrons with triiodide ions [1].
In order to enhance the photoelectric conversion efficiency $(\eta)$ of DSSC, addition of graphene into the P25 $\mathrm{TiO}_{2}$ film enhances the electron transport ability of the photoelectrode [4-6]. Graphene, the 2D carbon nanomaterial, causes widespread concern nowadays, which has drawn extensive attention because it has a high thermal conductivity (about $5000 \mathrm{~W} / \mathrm{mK}$ ), perfect mobility of charge that carries at room temperature (more than $200,000 \mathrm{~cm}^{2} / \mathrm{Vs}$ ), and high specific surface area (about reached $2630 \mathrm{~m}^{2} / \mathrm{g}$ ). Graphenebased hybrid nanomaterials have been widely applied in the photovoltaic devices, photocatalysts, and lithium-ion batteries. Herein, we incorporate the $2 \mathrm{D}$ graphene into $\mathrm{TiO}_{2}$ photoelectrode for the improvement of the photovoltaic performances of DSSC [7-13].

In this study, we investigate the effects of different seriesparallel connection modules on DSSCs. If the DSSC module uses only series connections and no parallel connections, 


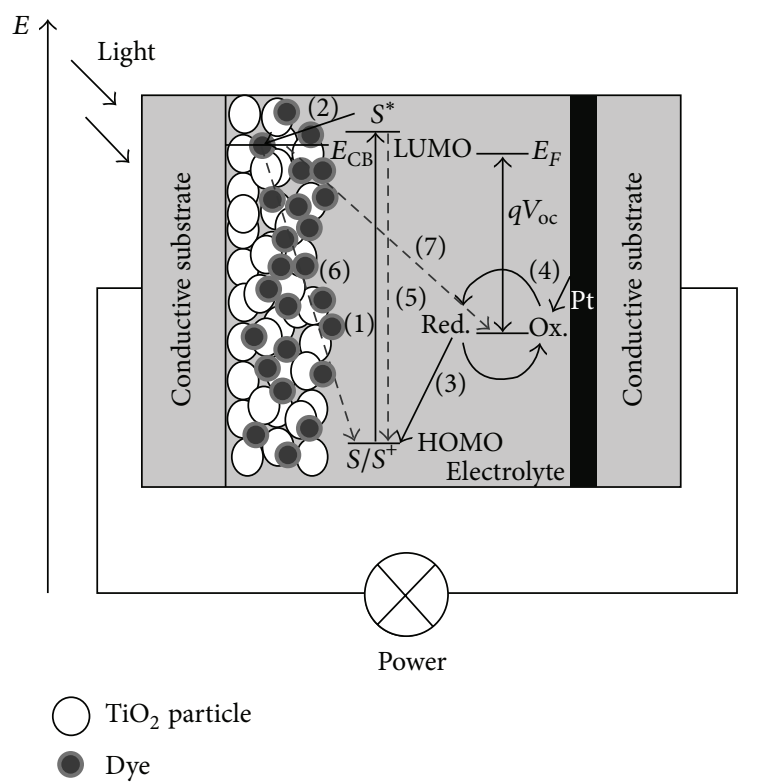

FIGURE 1: Working principle scheme of the dye-sensitized solar cell [1].

which can obtain easily higher voltage, but a module assembly is impossible to convert electrically because of lower current. Thus, an appropriate level parallel connection in the DSSC module assembly must be fabricated to produce current, composing parallel module assembly with minimum loss that is essential. That is to say, it is important to maintain large internal shunt resistance $\left(R_{\mathrm{SH}}\right)$ in the module assembly. The current loss is caused by decrease of internal shunt resistance, which can be inhibited by proper series connected [1].

\section{Materials and Methods}

2.1. Materials. Graphite powder was purchased from Enerage Inc., Taiwan. Titanium dioxide $\left(\mathrm{TiO}_{2}\right)$ powder and Ruthenium-535 (N3) were purchased from UniRegion Bio-Tech, Taiwan. The ethanol was purchased from Katayama Chemical, Japan. The Triton X-100 was purchased from PRS Panreac, Spain. The Acetylacetone (AcAc), lithium iodide (LiI), and 4-tert-butylpyridine (TBP) were purchased from SigmaAldrich, USA. The iodine $\left(\mathrm{I}_{2}\right)$ was purchased from Riedelde Haen, USA. The 1-propyl-2,3-dimethylimidazolium iodide (DMPII) was purchased from Tokyo Chemical, Japan.

2.2. Fabrication of Dye-Sensitized Solar Cell. The synthesis of graphene oxide $(\mathrm{GO})$ was reported in our previous paper [14]. The graphene/ $\mathrm{TiO}_{2}$ paste consisted of $\mathrm{P} 25 \mathrm{TiO}_{2}$ powder, deionized water, Triton X-100, acetoacetone (AcAc), and graphene oxide solution, which were mixed by an ultrasonic cleaner for 10 minutes. The graphene/ $\mathrm{TiO}_{2}$ paste was coated on fluorine doped $\mathrm{SnO}_{2}$-coated conductive (FTO) glass by spin-coated method. Then the graphene/ $/ \mathrm{TiO}_{2}$ layer was annealed at $550^{\circ} \mathrm{C}$ for 30 minutes as the working electrode. The working electrode was immersed in $3 \times 10^{-4} \mathrm{M} \mathrm{N} 3$ dye solution. Platinum $(\mathrm{Pt})$ layer was deposited for 90 seconds on the FTO-glass substrate as the counter electrode by using radio frequency (R.F.) sputtering system. After that the cell was sealed by Surlyn to form a sandwich structure. And the electrolyte solution consisted of $0.6 \mathrm{M}$ 1-propyl-2,3dimethylimidazolium iodide (DMPII), 0.5 M lithium iodide (LiI), $0.05 \mathrm{M}$ iodine $\left(\mathrm{I}_{2}\right)$, and $0.5 \mathrm{M}$ 4-tert-butylpyridine (TBP) in $15 \mathrm{~mL}$ 3-methoxypropionitrile (MPN). The active area of working electrode was approximately $0.57 \mathrm{~cm}^{2}$. A module assembly was fabricated with variations module assemblies by copper tape, using 8 DSSCs module assembly and having module areas of $16.32 \mathrm{~cm}^{2}$. Moreover, the total effective area of module assembly was approximately $4.56 \mathrm{~cm}^{2}$.

2.3. Characteristic and Photoelectric Properties of Graphene/ $\mathrm{TiO}_{2}$ Composite Films. The short circuit current density-open circuit voltage $(J-V)$ curves and photovoltaic characterizations of the DSSCs were carried out by using a Keithley 2400 source meter. A solar light simulator (MFS-PV-BasicHMT, Taiwan) was used to simulate sunlight under one sun AM1.5 G $\left(100 \mathrm{~mW} / \mathrm{cm}^{2}\right)$ illumination provided by a $1000 \mathrm{~W}$ Xenon (Xe) lamp. The electrochemical impedance spectroscopy (EIS) measurements were performed using an electrochemical analyzer (BioLogic SP-150, France) with forward bias of $0.70 \mathrm{~V}$ in the dark. The impedance spectra were recorded by EC-lab software within the frequency range from $50 \mathrm{mHz}$ to $1 \mathrm{MHz}$ by applying an AC perturbation signal of $10 \mathrm{mV}$.

\section{Results and Discussion}

3.1. Characterization of Graphene/TiO $\mathrm{T}_{2}$ Composite Film. The photoelectrode of DSSC is composed of graphene/ $\mathrm{TiO}_{2}$ composite film. The surface morphology of graphene/TiO composite film has been investigated using SEM. Figure 2 showed top-view SEM image of graphene/ $/ \mathrm{TiO}_{2}$ composite film. As shown in Figure 2, graphene/ $/ \mathrm{TiO}_{2}$ composite film had higher specific surface area, which attributed to the lower crystallinity and $\mathrm{TiO}_{2}$ nanoparticles that were attached on the graphene easily [14-16].

3.2. Photovoltaic Characterizations of DSSCs. An appropriate level parallel connection in the DSSC module assembly must be fabricated to produce current, composing parallel module assembly with minimum loss that is essential $[17,18]$. That is to say, it is important to maintain large internal shunt resistance $\left(R_{\mathrm{SH}}\right)$ in the module assembly. The current loss is caused by decrease of internal $R_{\mathrm{SH}}$, which can be inhibited by proper series connected [1].

Figure 3 showed real diagram of DSSC module assemblies. The module assembly was fabricated by 8 DSSCs, and these cells were listed in Table 1 . The average $V_{\mathrm{oc}}, J_{\mathrm{sc}}, \mathrm{FF}$, and $\eta$ of these cells were $0.648 \mathrm{~V}, 14.136 \mathrm{~mA} / \mathrm{cm}^{2}, 37.053 \%$, and $3.008 \%$, respectively.

3.3. Effect of Different Series-Parallel Connection Modules on Impedance Spectrum. As shown in Figure 4(a), the equivalent circuit of DSSC is demonstrated by using EIS. In the 


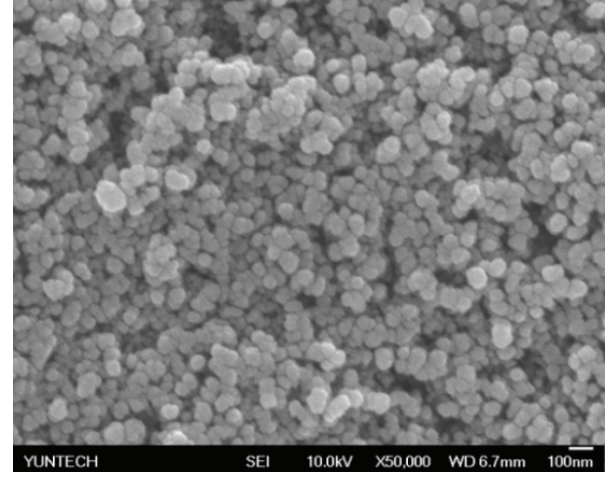

FIgURE 2: SEM images of graphene/ $\mathrm{TiO}_{2}$ composite film.

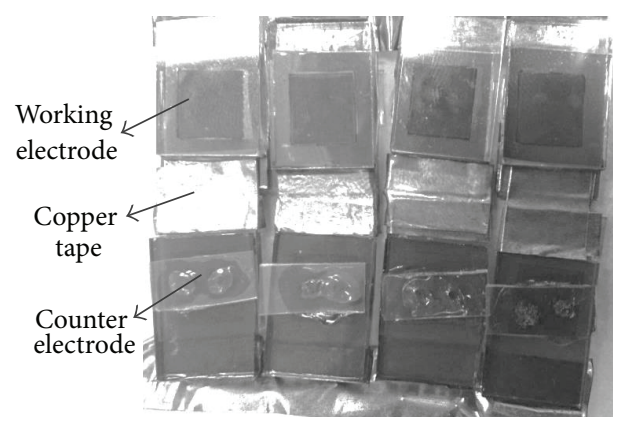

FIgURE 3: Real diagram of DSSC module assemblies.

TABLE 1: Photovoltaic properties of DSSCs.

\begin{tabular}{lcccc}
\hline Sample & $V_{\mathrm{oc}}(\mathrm{V})$ & $J_{\mathrm{sc}}\left(\mathrm{mA} / \mathrm{cm}^{2}\right)$ & F.F. $(\%)$ & $\eta(\%)$ \\
\hline 1 & 0.63 & 14.96 & 37.69 & 3.15 \\
2 & 0.62 & 13.96 & 37.52 & 2.88 \\
3 & 0.70 & 13.05 & 35.04 & 2.85 \\
4 & 0.67 & 13.75 & 36.76 & 3.00 \\
5 & 0.66 & 13.92 & 36.94 & 3.01 \\
6 & 0.64 & 14.45 & 37.35 & 3.05 \\
7 & 0.63 & 14.52 & 37.40 & 3.06 \\
8 & 0.63 & 14.48 & 37.72 & 3.06 \\
Standard & 0.027 & 0.592 & 0.881 & 0.099 \\
deviation $(\delta)$ & & & & \\
Mean & 0.648 & 14.136 & 37.053 & 3.008 \\
\hline
\end{tabular}

equivalent circuit of DSSC, a diode represents the electrical properties of the pn-junction, and a $R_{\mathrm{SH}}$ and a constantcurrent source $\left(I_{S}\right)$ are in parallel with the junction, where $Q_{1}$ and $Q_{2}$ can be ignored in DC analysis because capacitances are too large, approximately $10 \mu \mathrm{F} / \mathrm{cm}^{2}$ and $1 \mathrm{mF} / \mathrm{cm}^{2}$, respectively. As shown in Figure 4(b), the equivalent circuit of DSSC can be simplified to Norton's equivalent circuit theorem by a current source $\left(I_{\mathrm{S}}\right)$ with series resistance $\left(R_{\mathrm{S}}\right)$ and $R_{\mathrm{SH}}$ in parallel, where the sum of $R_{1}, R_{2}, R_{3}$, and $W_{4}$ is expressed as $R_{\mathrm{S}}$. Also, the equivalent circuit of DSSC can be simplified to Thevenin's equivalent circuit theorem by a voltage source $V_{\mathrm{S}}$ with $R_{\mathrm{S}}$ and $R_{\mathrm{SH}}$ in series, as shown in Figure 4(c). And the sum of $R_{\mathrm{S}}$ and $R_{\mathrm{SH}}$ is expressed as $R$, in which the output current $\left(I_{\mathrm{O}}\right)$ is equal to " $\left(R_{\mathrm{SH}} \times I_{\mathrm{S}}\right) / R$," but $I_{\mathrm{O}}$ is generally similar with $I_{\mathrm{S}}$ because $R_{\mathrm{SH}}$ is much larger than RS [1].

The internal resistance, the characterization of electron and charge transportation, and diffusion between interfaces were simulated by an RC parallel circuit [19]. The equivalent circuit model was described as follows:

$$
R_{1}+\frac{R_{2}}{Q_{1}}+\frac{\left(R_{3}+W_{4}\right)}{Q_{2}},
$$

where $R_{1}$ corresponds to the serial resistances of FTO-glass and wires are at the high-frequency region. $R_{2}$ and $Q_{1}$ correspond to the resistance and double layer capacitance of the electrolyte/Pt-FTO interface. $R_{3}$ and $Q_{2}$ correspond to the resistance and chemical capacitance of the $\mathrm{TiO}_{2}$ /electrolyte interface. $W_{4}$ is the Warburg impedance, which describes the diffusion of $\mathrm{I}_{3}{ }^{-}$in the electrolyte. The symbol $Q$, also known as constant phase elements (CPE), describes the constant phase element of the capacitance, meaning a nonideal frequency dependent capacitance due to a nonuniform distribution of current by the material heterogeneity $[4,20$, 21].

As shown in Figures 5(a) and 5(b), the cells were connected module assembly in series connection, which was represented as $\mathrm{S}$, two cells in series were denoted as $2 \mathrm{~S}$, and so on. In the series-connected models, the impedance was enlarged with increasing module assemblies in series connection, which could be attributed to the longer conductive path for electron. The longer conductive path for electron would easily make the condition of electron recombination happen during the electron transfer from conduction band of $\mathrm{TiO}_{2}$ to $\mathrm{I}_{3}{ }^{-}$in electrolyte. Besides, the result of series connection was beneficial to raise voltage of DSSC, but the current density of DSSC remained unchanged.

On the other hand, Figure 6 showed that the module assemblies were fabricated in parallel connection, where parallel connection was represented as $\mathrm{P}$, two cells in parallel were represented as $2 \mathrm{P}$, and so on. In the parallel connected models, the impedance was reduced with increasing module assemblies in parallel connection, which could be attributed to more conductive paths for electron. Besides, the result of parallel connection was beneficial to raise current but the voltage remained unchanged.

In the series-parallel connected models, series connection can maintain large shunt resistance. Figure 7(a) showed the series-parallel connected models by composing 2 series connections and 4 parallel connections, where 2 series connections and 4 parallel connections were represented as $2 \mathrm{~S} 4 \mathrm{P}$. The total internal shunt resistance was equal to $1 / 2 R_{\mathrm{SH}}$. Therefore, the number of series connected DSSCs is less than the number of parallel connected DSSCs, in which the total internal shunt resistance is lower than one cell, in spite of the additional parallel connections [1]. On the contrary, Figure 7(b) showed the series-parallel connected models by composing 4 series connections and 2 parallel connections, where 4 series connections and 2 parallel connections were represented as $4 \mathrm{~S} 2 \mathrm{P}$. The total internal shunt resistance was equal to $2 R_{\mathrm{SH}}$. 


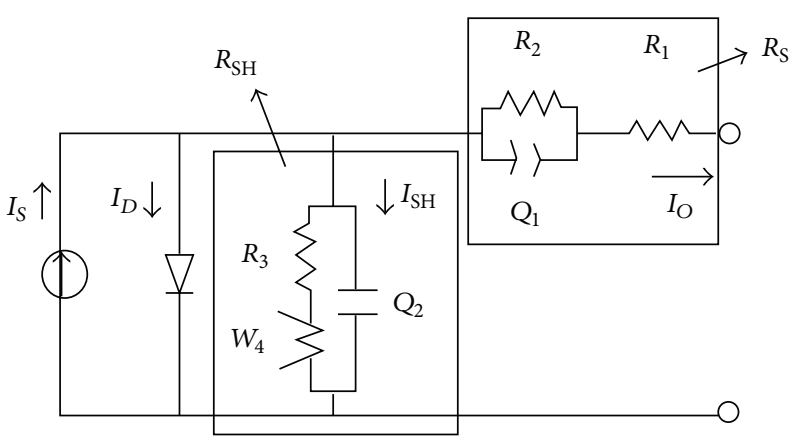

(a)

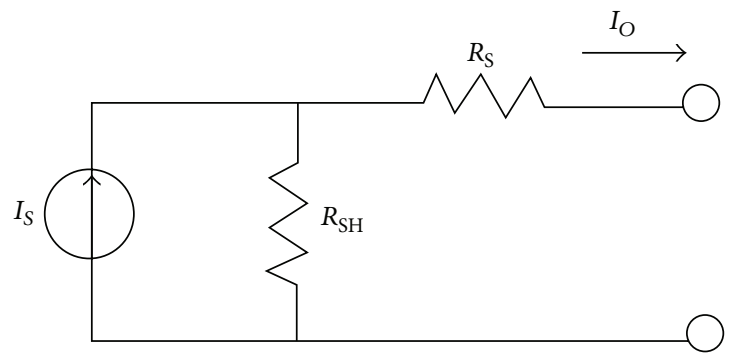

(b)

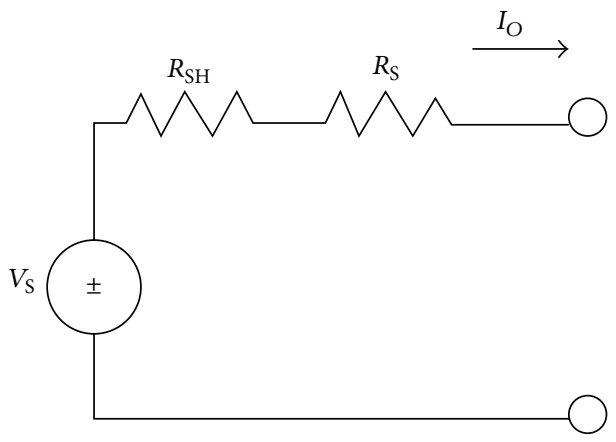

(c)

Figure 4: (a) Equivalent circuit of DSSC; simplified equivalent circuit of DSSC by (b) Norton's equivalent circuit theorem; (c) Thevenin's equivalent circuit theorem [1].

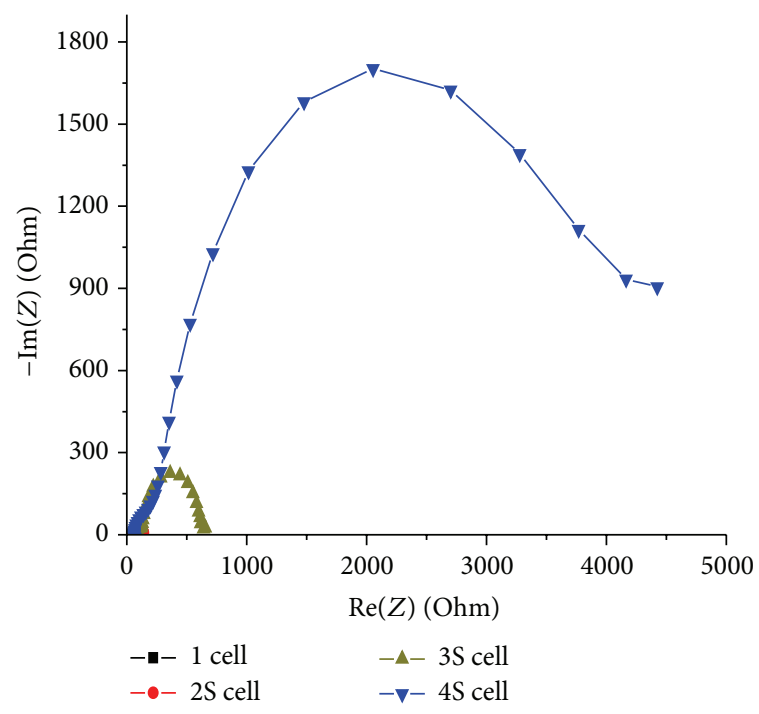

(a)

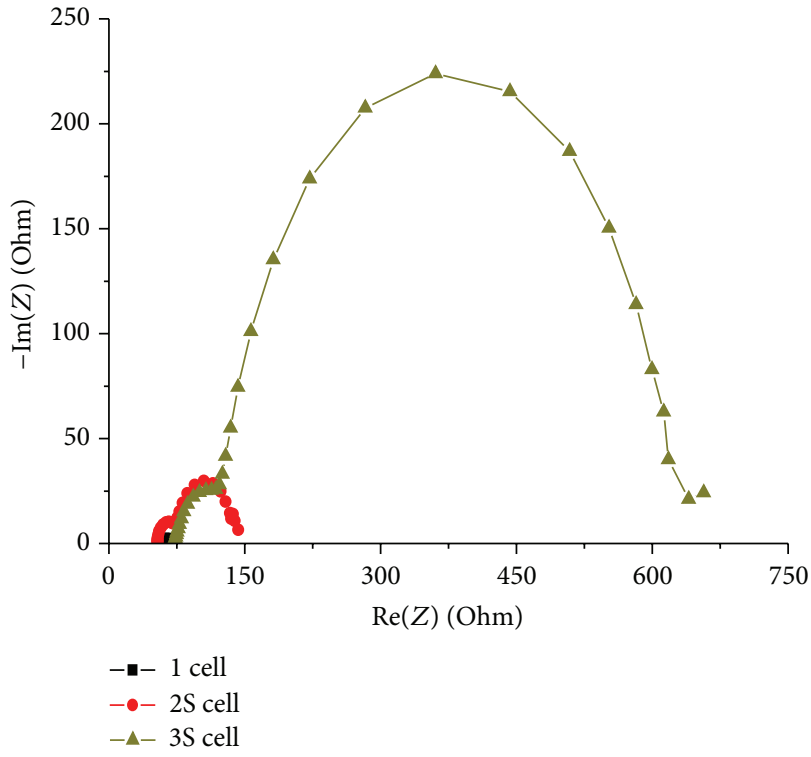

(b)

FIgURE 5: (a) Cells connected module assembly in series connection; (b) an enlarged view.

As shown in Figure 8(a), the series connected models were composed by 1-4 cells in series connection, the characteristic frequency shifted toward low frequency with increase of series connected cell due to enhancement of shunt resistance. On the other hand, Figure $8(\mathrm{~b})$ showed parallel connected models by composing 1-4 cells, in which the lifetime $\left(\tau_{e}\right)$ did not have significant change, and the characteristic frequency was almost constant because the time constants $\left(\tau_{n}\right)$ were almost the same. Thus, the number of series connected DSSCs was more than the number of parallel connected DSSCs, in which the characteristic peaks were toward low frequency, as shown in Figure 8(c). 


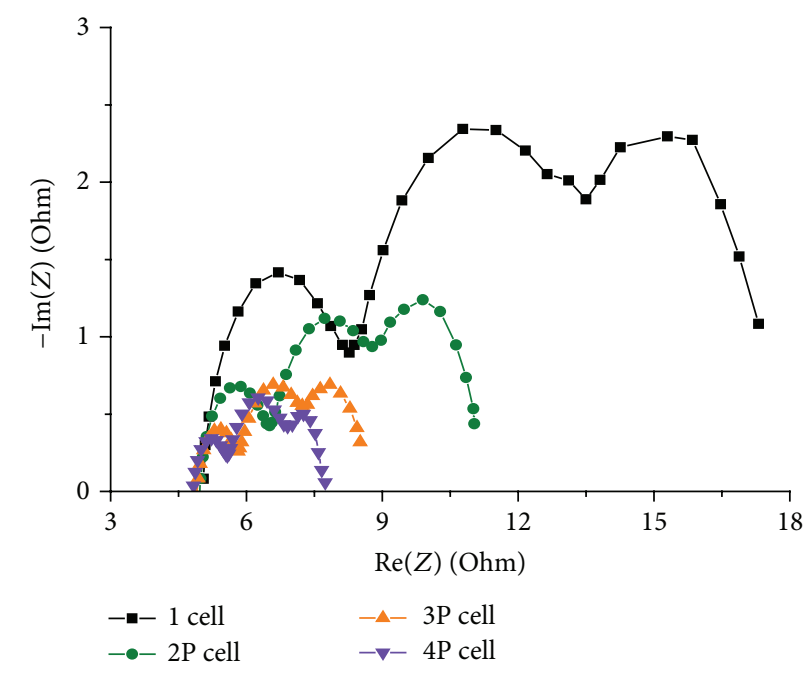

FiguRE 6: Cells connected module assembly in parallel connection.

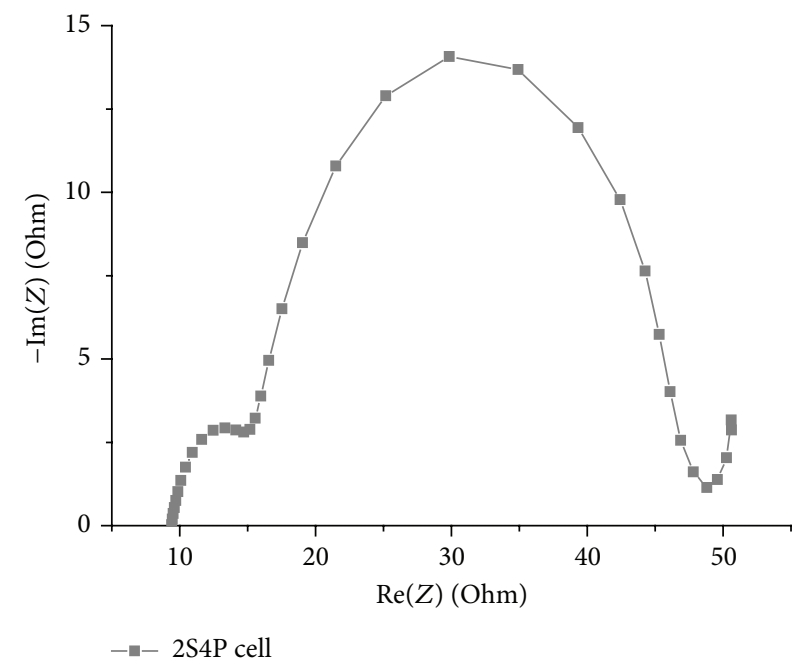

(a)

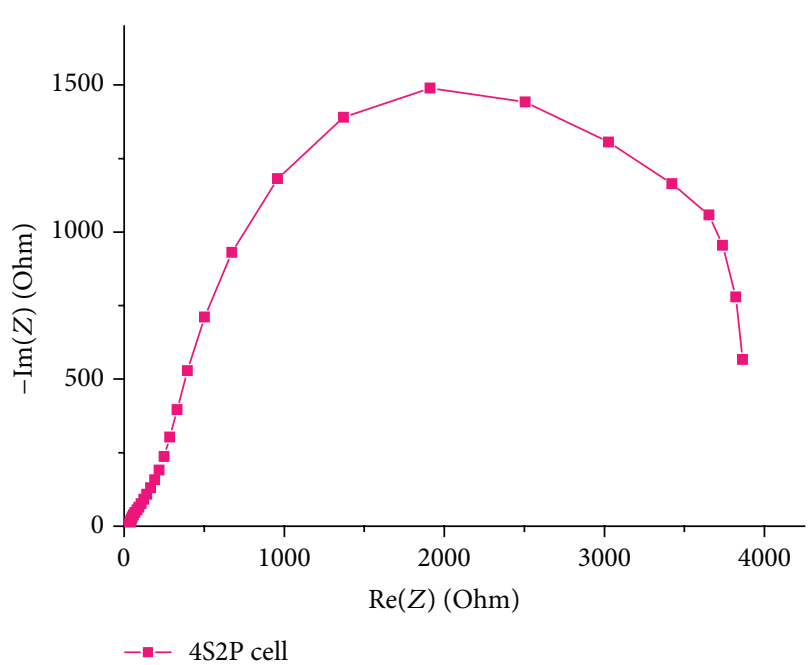

(b)

FIGURE 7: Nyquist plots based on different DSSC model assemblies (a) series-parallel module: 2S4P; (b) series-parallel module: 4S2P.

In Figures 9(a)-9(c), the trends of impedances were consistent with Figures $5-7 . R_{\mathrm{S}}$, total series resistance is composed by charge-transfer resistances and Nernst diffusion resistance in DSSC, using conductive substrate with very low sheet resistance, a counter electrode with very large roughness factor (RF), and low $R_{3}$ to obtain the minimum series resistance theoretically of $0.7 \mathrm{~cm}^{2}$. However, the actual series resistance is much higher [22]. And the EIS results were listed in Table 2.

Based on Table 2, $R_{1}$ mainly attributed to the sheet resistance of conductive substrate, in which $R_{1}$ increases in proportion to increasing in the sheet resistance of conductive substrate [21]. In addition, $R_{2}$ is related to charge-transfer process at the counter electrode, which increases with larger surface area of the counter electrode. In order to decrease $R_{2}$, $\mathrm{RF}$ acts as an index of surface area of the counter electrode, which is defined as the ratio of the total surface area to the active area of the counter electrode [22].

\section{Conclusions}

In this study, the internal impedances of different DSSC models were analyzed by electrochemical impedance spectrometer with an equivalent circuit model. It was useful to analyze the component structure and promote photovoltaic properties of DSSC. According to the experiment results, the impedance was increased with increasing cells connected in series. On the contrary, the impedance was decreased with increasing cells connected in parallel. In addition, the cells were composed by 1-4 cells in series connection; the characteristic frequency shifted toward low frequency with increase of series connected cell due to enhancement of 


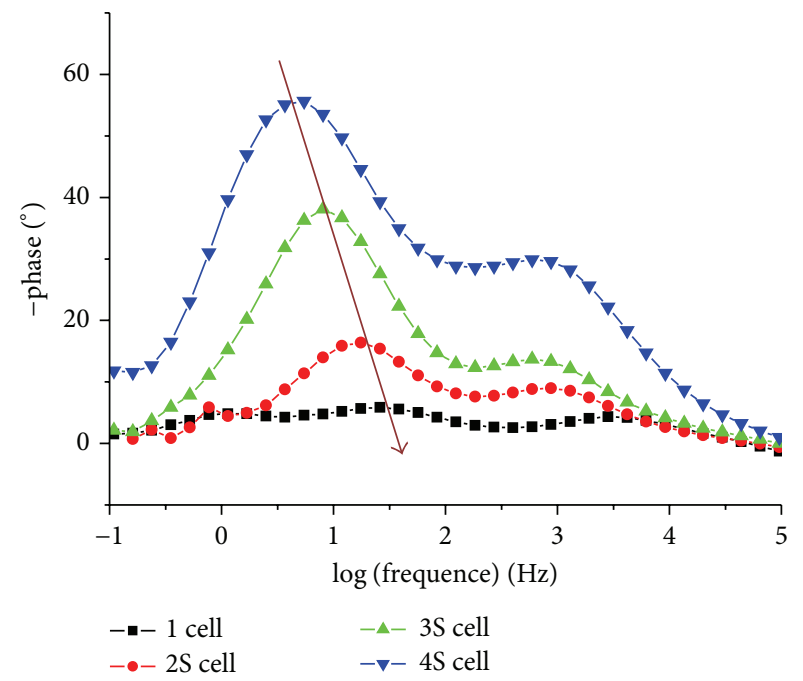

(a)

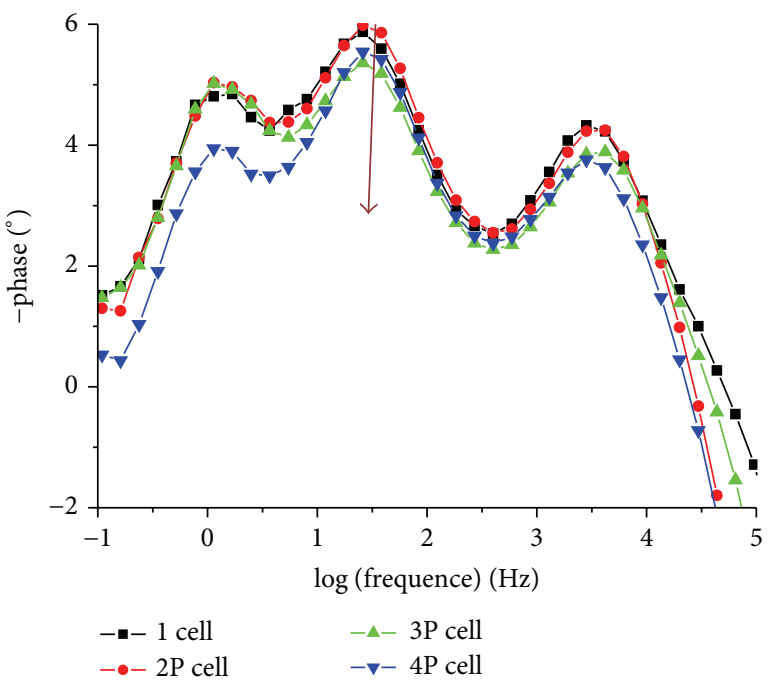

(b)

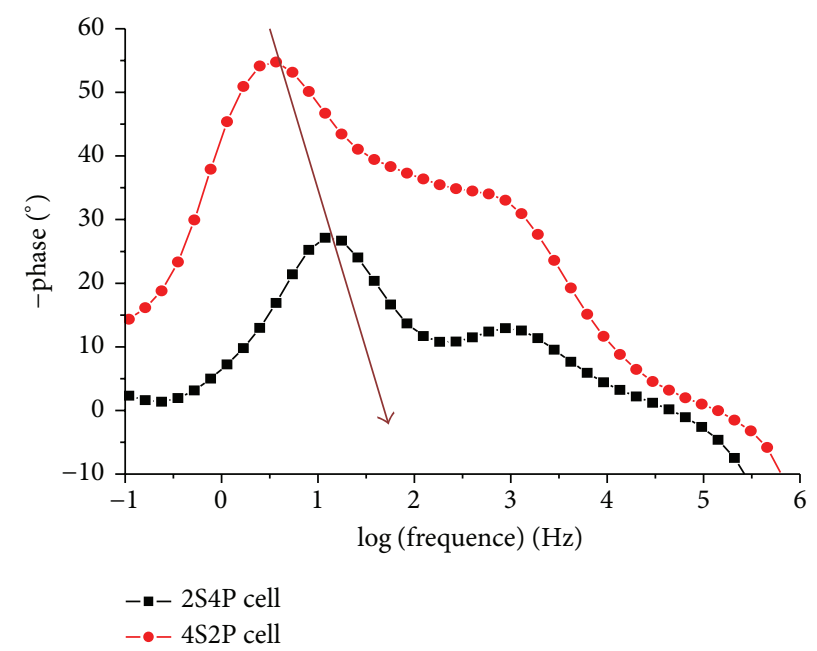

(c)

FIGURE 8: The Bode phase plots based on different DSSC model assemblies (a) series modules; (b) parallel modules; (c) series-parallel modules.

TABLE 2: Measurement results of EIS based on different DSSC model assemblies.

\begin{tabular}{lccccccccc}
\hline Models & $R_{1}(\Omega)$ & $R_{2}(\Omega)$ & $Q_{1}(\mu \mathrm{F})$ & $R_{3}(\Omega)$ & $Q_{2}(\mathrm{mF})$ & $W_{4}(\Omega)$ & $\omega_{\min }(\mathrm{Hz})$ & $\tau_{e}(\mathrm{~ms})$ & $\tau_{n}(\mathrm{~ms})$ \\
\hline 1 cell & 17.05 & 3.31 & 39.63 & 6.29 & 3.87 & 2.38 & 5.87 & 170.23 & 24.34 \\
2S & 53.62 & 19.28 & 18.08 & 63.64 & 0.45 & 12.77 & 16.38 & 61.05 & 28.64 \\
3S & 72.64 & 69.09 & 15.68 & 477.41 & 0.19 & 38.95 & 38.10 & 26.25 & 90.71 \\
$4 \mathrm{~S}$ & 59.06 & 196.32 & 6.76 & 3589.32 & 0.08 & 341.15 & 55.64 & 17.97 & 287.15 \\
2P & 9.15 & 1.84 & 82.78 & 2.43 & 5.46 & 2.06 & 5.36 & 186.58 & 13.27 \\
3P & 4.90 & 1.07 & 139.66 & 1.55 & 8.84 & 1.16 & 5.98 & 167.13 & 13.70 \\
$4 \mathrm{P}$ & 4.83 & 0.79 & 163.41 & 1.36 & 10.06 & 0.98 & 5.54 & 180.51 & 13.68 \\
2S4P & 9.42 & 7.84 & 91.32 & 35.96 & 1.40 & 2.78 & 27.13 & 36.86 & 50.34 \\
4 S2P & 35.68 & 88.98 & 7.20 & 3384.19 & 0.14 & 442.11 & 54.75 & 18.26 & 473.79 \\
\hline
\end{tabular}




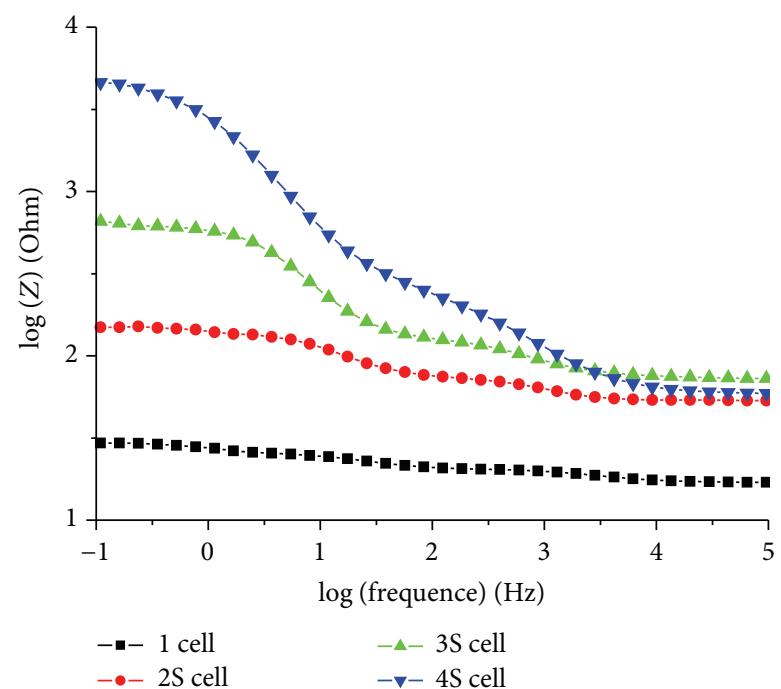

(a)

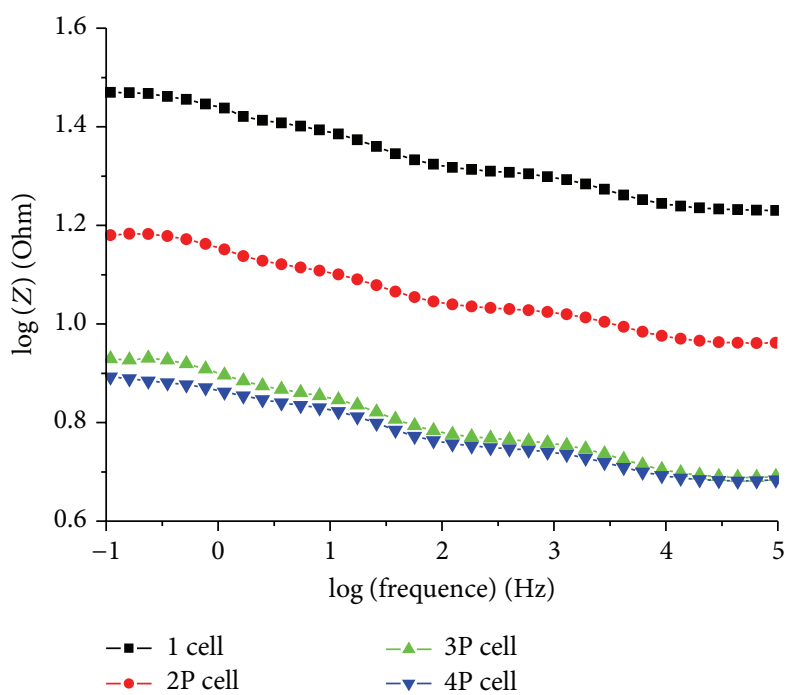

(b)

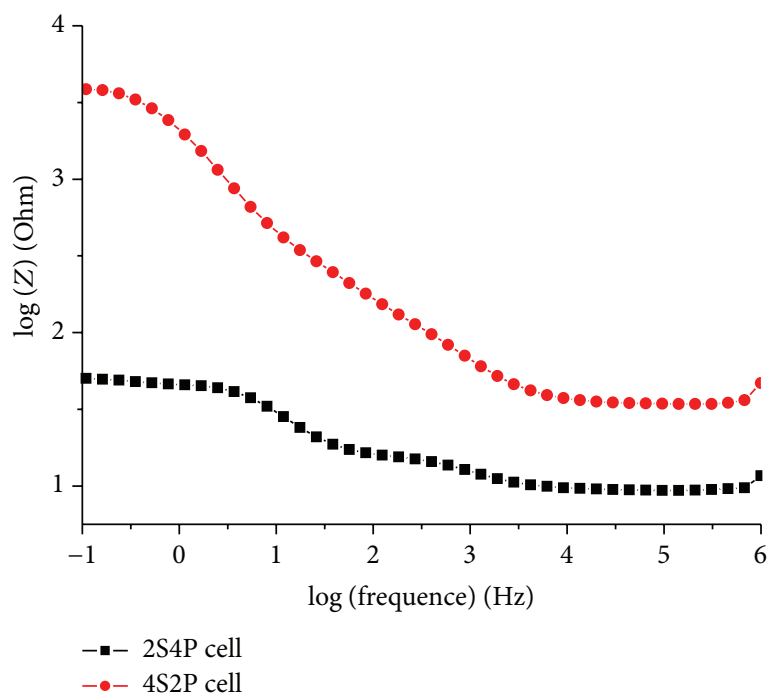

(c)

FIGURE 9: Bode impedance plots based on different DSSC model assemblies (a) series modules; (b) parallel modules; (c) series-parallel modules.

shunt resistance. Conversely, the cells were shown parallel connected models by composing 1-4 cells, in which the lifetime did not have significant change, and the characteristic frequency was almost constant because the time constants were almost the same.

\section{Competing Interests}

The authors declare that they have no competing interests.

\section{Acknowledgments}

This study has been supported by Ministry of Science and Technology, China, under the Contracts MOST 103-2221-E224-073 and MOST 104-2221-E-224-030.

\section{References}

[1] L. Andrade, J. Sousa, H. Aguilar Ribeiro, and A. Mendes, "Phenomenological modeling of dye-sensitized solar cells under transient conditions," Solar Energy, vol. 85, no. 5, pp. 781-793, 2011.

[2] H. Seo, M.-K. Son, J.-K. Kim et al., "Analysis of current loss from a series-parallel combination of dye-sensitized solar cells using electrochemical impedance spectroscopy," Photonics and Nanostructures-Fundamentals and Applications, vol. 10, no. 4, pp. 568-574, 2012.

[3] M. K. Nazeeruddin, F. De Angelis, S. Fantacci et al., "Combined experimental and DFT-TDDFT computational study of photoelectrochemical cell ruthenium sensitizers," Journal of the American Chemical Society, vol. 127, no. 48, pp. 16835-16847, 2005. 
[4] L. Andrade, R. Cruz, H. A. Ribeiro, and A. Mendes, "Impedance characterization of dye-sensitized solar cells in a tandem arrangement for hydrogen production by water splitting," International Journal of Hydrogen Energy, vol. 35, no. 17, pp. 88768883, 2010.

[5] M. Motlak, N. A. M. Barakat, M. S. Akhtar et al., "Influence of $\mathrm{GO}$ incorporation in $\mathrm{TiO}_{2}$ nanofibers on the electrode efficiency in dye-sensitized solar cells," Ceramics International, vol. 41, no. 1, pp. 1205-1212, 2015.

[6] H. D. Jang, E. H. Jo, H. Chang, J. Kim, and K.-M. Roh, "Incorporation of 3D crumpled graphene in nanostructured $\mathrm{TiO}_{2}$ films for dye-sensitized solar cells," Materials Letters, vol. 142, pp. 304-307, 2015.

[7] H. Zhang, X. Lv, Y. Li, Y. Wang, and J. Li, "P25-graphene composite as a high performance photocatalyst," ACS Nano, vol. 4, no. 1, pp. 380-386, 2010.

[8] X. Luan, L. Chen, J. Zhang, G. Qu, J. C. Flake, and Y. Wang, "Electrophoretic deposition of reduced graphene oxide nanosheets on $\mathrm{TiO}_{2}$ nanotube arrays for dye-sensitized solar cells," Electrochimica Acta, vol. 111, pp. 216-222, 2013.

[9] X. Xu, D. Huang, K. Cao, M. Wang, S. M. Zakeeruddin, and M. Grätzel, "Electrochemically reduced graphene oxide multilayer films as efficient counter electrode for dye-sensitized solar cells," Scientific Reports, vol. 3, article 1489, 2013.

[10] M. Song, H.-K. Seo, S. Ameen, M. S. Akhtar, and H.-S. Shin, "Low resistance transparent graphene-like carbon thin film substrates for high performance dye sensitized solar cells," Electrochimica Acta, vol. 115, pp. 559-565, 2014.

[11] Y. Gao, H.-L. Yip, S. K. Hau et al., "Anode modification of inverted polymer solar cells using graphene oxide," Applied Physics Letters, vol. 97, no. 20, Article ID 203306, 2010.

[12] Y. Gao, H.-L. Yip, K.-S. Chen et al., "Surface doping of conjugated polymers by graphene oxide and its application for organic electronic devices," Advanced Materials, vol. 23, no. 16, pp. 1903-1908, 2011.

[13] N. Yang, J. Zhai, D. Wang, Y. Chen, and L. Jiang, "Twodimensional graphene bridges enhanced photoinduced charge transport in dye-sensitized solar cells," ACS Nano, vol. 4, no. 2, pp. 887-894, 2010.

[14] W. Shu, Y. Liu, Z. Peng, K. Chen, C. Zhang, and W. Chen, "Synthesis and photovoltaic performance of reduced graphene oxide- $\mathrm{TiO}_{2}$ nanoparticles composites by solvothermal method," Journal of Alloys and Compounds, vol. 563, pp. 229-233, 2013.

[15] J.-C. Chou, C.-H. Huang, Y.-H. Liao, S.-W. Chuang, L.-H. Tai, and Y.-H. Nien, "Effect of different graphene oxide contents on dye-sensitized solar cells," IEEE Journal of Photovoltaics, vol. 5, no. 4, pp. 1106-1112, 2015.

[16] T.-H. Tsai, S.-C. Chiou, and S.-M. Chen, "Enhancement of dyesensitized solar cells by using graphene- $\mathrm{TiO}_{2}$ composites as photoelectrochemical working electrode," International Journal of Electrochemical Science, vol. 6, no. 8, pp. 3333-3343, 2011.

[17] J. Wu, Y. Xiao, Q. Tang et al., "A large-area light-weight dyesensitized solar cell based on all titanium substrates with an efficiency of $6.69 \%$ outdoors," Advanced Materials, vol. 24, no. 14, pp. 1884-1888, 2012.

[18] C. H. Ku and J. J. Wu, "Electron transport properties in $\mathrm{ZnO}$ nanowire array/nanoparticle composite dye-sensitized solar cells," Applied Physics Letters, vol. 91, Article ID 093117, pp. 1-3, 2007.

[19] C. H. Huang, J. C. Chou, S. W. Chuang et al., "Effect of graphene/ $/ \mathrm{TiO}_{2}$ composites photoelectrode on dye-sensitized solar cells," in Proccedings of the 19th Annual Conference of Chemical Sensors, pp. 23-26, Taipei, Taiwan, May 2014.

[20] N. Koide, A. Islam, Y. Chiba, and L. Han, "Improvement of efficiency of dye-sensitized solar cells based on analysis of equivalent circuit," Journal of Photochemistry and Photobiology A: Chemistry, vol. 182, no. 3, pp. 296-305, 2006.

[21] C. H. Huang, J. C. Chou, Y. H. Liao, Y. J. Lin, C. M. Chu, and Y. H. Nien, "Analysis of different dye-sensitized solar cell models by electrochemical impedance spectroscopy," in Proceedings of the IEEE Conference on Electron Devices and Solid-State Circuits, pp. 29-32, Singapore, June 2015.

[22] C. C. Chen, W.-D. Jheng, and C.-K. Lin, "Large-area $\mathrm{TiO}_{2}$ nanotube dye-sensitized solar cells using thermal-sprayed $\mathrm{Ti}$ layers on stainless steel," Ceramics International, vol. 40, no. 2 , pp. 3221-3226, 2014. 

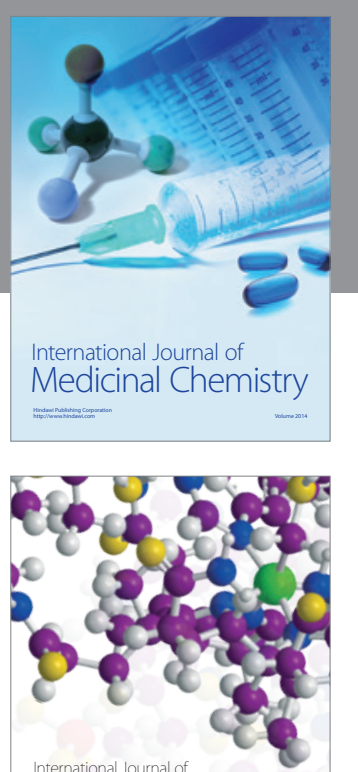

Carbohydrate Chemistry

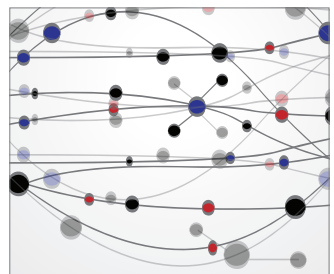

The Scientific World Journal
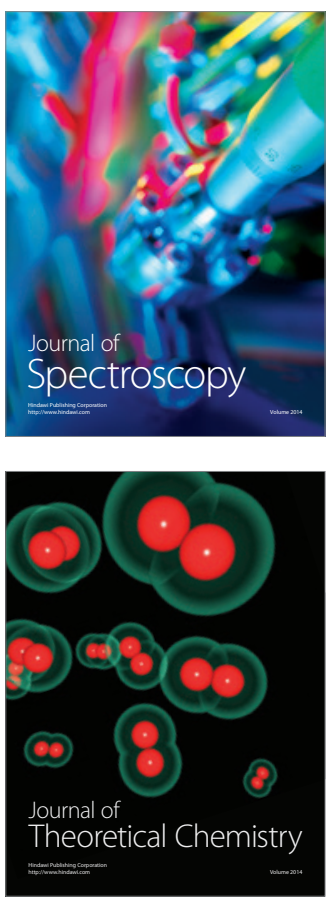
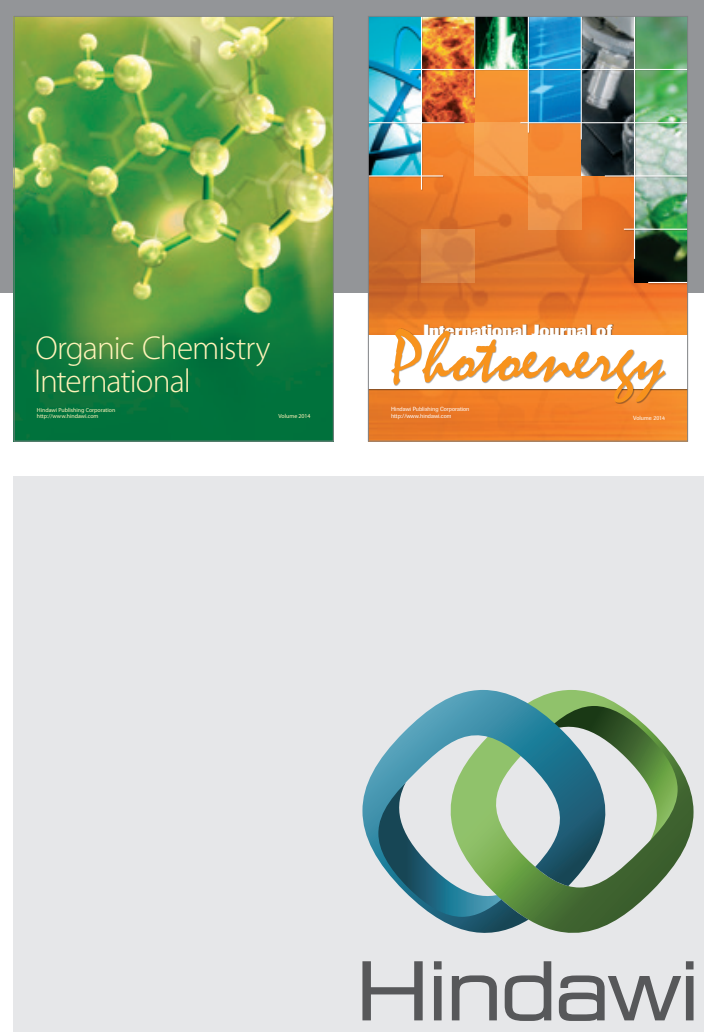

Submit your manuscripts at

http://www.hindawi.com

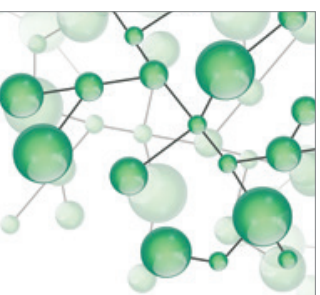

International Journal of

Inorganic Chemistry

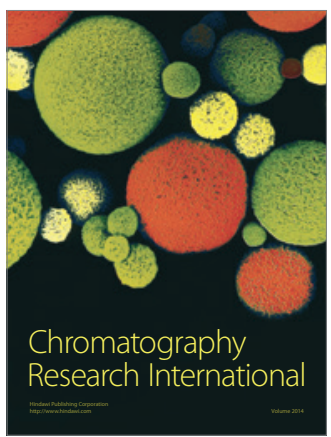

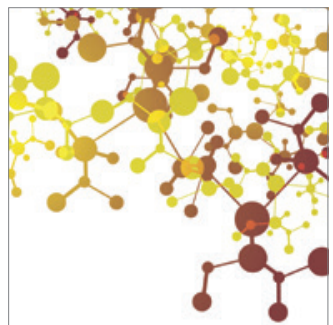

Applied Chemistry
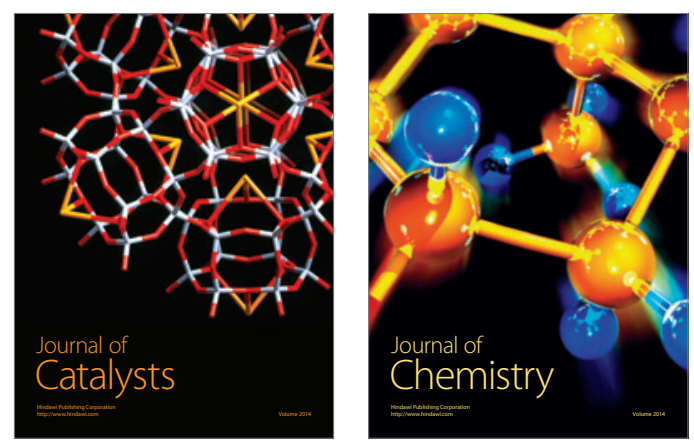
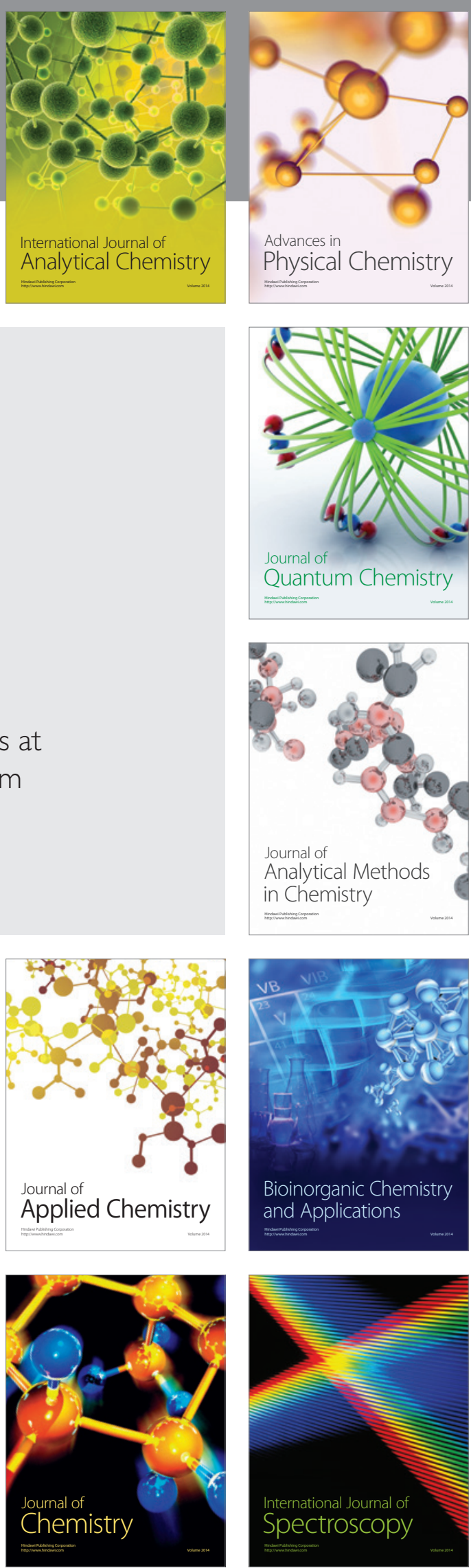